\title{
Effect of fibrinogen concentrate on clot strength in trauma: preliminary results of an in vitro study
}

\author{
MAS Meyer ${ }^{1 *}$, AM Sørensen ${ }^{2}$, PI Johansson ${ }^{1}$ \\ From London Trauma Conference \\ London, UK. 22-24 June 2011
}

\section{Background}

Fibrinogen supplementation in trauma has been suggested in order to restore or improve haemostatic competence; this could possibly reduce or replace the need for transfusions in case of bleeding. Results from functional haemostatic assays indicate that lowered clot strength is associated with a risk for massive transfusions [1]. The optimal fibrinogen concentration or indications for supplementation in trauma patients have not been established [2].

\section{Aim}

To examine the in vitro effect of adding fibrinogen concentrate to whole blood from trauma patients by Thrombelastography (TEG).

\section{Methods}

Eleven patients with severe injury admitted to a Danish level 1 trauma centre were enrolled in the study. Inclusion was based on: systolic pressure $<100 \mathrm{mmHg}$ and/or GCS $\leq 8$ and/or substantial bleeding. Eight out of eleven patients received a transfusion within $12 \mathrm{~h}$ after hospital admission. Mechanisms of injury included: road traffic accidents, fall injuries, and stab- and gunshot wounds. A citrated blood sample was obtained at admittance. TEG analyses were performed using both citrated kaolin (CK) and functional fibrinogen (FF). CK clot strength (maximum amplitude; MA) reflecting both the platelet and the fibrinogen contribution were compared to that of FF, which solely reflects fibrinogen contribution to clot strength. Volumes of fibrinogen concentrate equivalent to $6 \mathrm{~g}^{*} 75 \mathrm{~kg}^{-1}$ were added to samples prior to TEG analysis. $p<0.05$ was considered significant.

\section{Results}

Fibrinogen concentrate increased the clot strength in both CK and FF assays (Fig.1). CK MA increased by $8 \%$ $(p=0.013)$ and FF MA by $44 \%(p=0.005)$ after addition of fibrinogen concentrate.

\section{Conclusions}

In whole blood from trauma patients with severe injury, fibrinogen concentrate administered in a dose equivalent to $6 g^{7} 75 \mathrm{~kg}^{-1}$ increased clot strength significantly. These results indicate a possible pro-haemostatic effect of fibrinogen concentrate in severely injured trauma patients.

\section{Author details \\ ${ }^{1}$ Section for Transfusion Medicine, Capital Region Blood Bank, Copenhagen University Hospital, Copenhagen, Denmark. ${ }^{2}$ Department of Anaesthesia and the Trauma Center, Center of Head and Orthopaedics, Copenhagen University Hospital, Copenhagen, Denmark.}

Published: 22 March 2012

\section{References}

1. Leemann H, Lustenberger T, Talving P, Kobayashi L, Bukur M, Brenni M, Bruesch M, Spahn DR, Keel MJ: The role of rotation thromboelastometry in early prediction of massive transfusion. J Trauma 2010, 69(6):1403-1408.

2. Meyer MA, Ostrowski SR, Windelov NA, Johansson Pl: Fibrinogen concentrates for bleeding trauma patients: what is the evidence? Vox Sang 2011.

doi:10.1186/1757-7241-20-S1-O2

Cite this article as: Meyer et al:: Effect of fibrinogen concentrate on clot strength in trauma: preliminary results of an in vitro study. Scandinavian Journal of Trauma, Resuscitation and

Emergency Medicine 2012 20(Suppl 1):O2. 